\title{
Invocation by Laughter
}

$\mathrm{O}$, burst out laughing, laughers!

$\mathrm{O}$, laugh out loud, laughers!

You who laugh with laughs and you who laugh it up laughishly,

$\mathrm{O}$, laugh out loud, laugheringly!

$\mathrm{O}$, belaughable laughingstocks - the laughter of laughering laughers!

$\mathrm{O}$, unlaugh it enlaughingly, the laughter of onlaughing laughermen!

Laughterling, laughterling,

Uplaugh, downlaugh, laughlings, laughlings,

Laughsies, laughsies.

$\mathrm{O}$, burst out laughing, laughers!

$\mathrm{O}$, laugh out loud, laughers!

Velimir Khlebnikov, 1908-1909

First published in N.I. Kulbin (ed.), Studiya impressionistov, vol. 1 (Saint Petersburg: Izdatelstvo N.I. Butkovskoi, 1910), 47. 
This page intentionally left blank 